\title{
Assessment of islet cell viability using fluorescent dyes
}

\author{
H. L. Bank \\ Department of Pathology and Laboratory Medicine, Medical University of South Carolina, Charleston, South Carolina, USA
}

\begin{abstract}
Summary. A rapid fluorometric method has been developed to evaluate the viability of isolated islet cells. The assay differentiates between viable and nonviable cells by the simultaneous use of the inclusion and exclusion dyes acridine orange and propidium iodide. When viewed by fluorescent microscopy, viable cells fluoresce green, while nonviable cells fluoresce bright red. Although the acridine orange and propidium iodide assay measures membrane integrity, the results of this assay correlate with other measures of cell viability. Compared to trypan blue exclusion, this assay is easier to read, more stable, and has fewer staining artifacts. The assay enables the rapid estimation of the viability of a population
\end{abstract}

of islet cells prior to time-consuming experiments rather than retrospectively. This assay can also be used with intact islets. Stained islets can be divided into three distinct groups: green fluorescing islets contain insulin, red fluorescing islets contain little or no insulin and a third class of islets containing some non-viable cells fluoresce red, green, and yellow. The yellow colour is due to the superimposition of red and green fluorescing cells.

Key words: Islet viability, fluorochromes, B cells, acridine orange, propidium iodide, trypan blue exclusion, membrane integrity.
A reliable method for rapidly determining the viability of isolated islet cells would be useful in studies on transplantation, cryopreservation, insulin release, and biosynthesis. Functional assays to determine insulin content or release and morphological assays including histochemistry or electron microscopy are time-consuming and expensive for routine viability assays.

An alternative approach uses inclusion and/or exclusion dyes to test the integrity of the plasma membrane. Several fluorometric dyes were tested as indicators of membrane integrity. Fluorescein diacetate (FDA) has been used as a fluorometric assay of cell viability. FDA is a nonpolar ester which passes through plasma membranes and is hydrolysed by intracellular esterases to produce free fluorescein. The polar fluorescein is confined within cells with an intact plasma membrane and can be observed under appropriate excitation conditions [1-4]. However, staining of islet cells with FDA results in high background fluorescence. This fluorescence is presumably due to extracellular hydrolysis of the FDA or to fluorescein that leaked through damaged membranes.

Acridine orange (AO) is a membrane-permeable, monovalent, cationic dye $[5,6]$ which binds to nucleic acids. A low concentration of AO causes a green fluorescence, while a high concentration causes a red fluo- rescence. Propidium iodide (PI) is impermeable to intact plasma membranes, but it easily penetrates the plasma membrane of dead or dying cells [7] and intercalates with DNA or RNA forming a bright red fluorescent complex [8-11]. Both intracellular and extracellular background fluorescence is minimal after staining with optimal concentrations of these dyes.

A combination of low concentrations of $\mathrm{AO}$ and PI was evaluated as a viability assay for islet cell suspensions. This combination of fluorochromes permits the simultaneous observation of cells with intact and with compromised plasma membranes [12]. However, any new assays must be compared with classical assays of cell "viability". In this report the AO/PI assay is compared to the traditional trypan blue exclusion assay. The stability, cytotoxicity, and reproducibility of the assay was evaluated on isolated islet cells derived from adult rat. In addition, the assay was applied to islet cells derived from mice, dogs and neonatal humans and to isolated intact rat islets.

\section{Materials and methods}

All National Institute of Health and institutional Animal Research Committee guidelines for the welfare of research animals were followed. Long Evans Hooded (LEH) male rats (220-250 g) were fast- 
ed for 12 to $18 \mathrm{~h}$ before the isolation of the islets. Pancreatic islets of Langerhans were isolated using the collagenase isolation procedure described previously [13, 14]. A single step, 11\% Ficoll (LSM, Bionetics Lab, Litton, Kensington, Md, USA) separation was used to separate islets from the tissue digest [14]. The islets were collected at the buffer/ficoll interface, and washed with phosphate buffered saline (PBS).

Rat islets were dissociated with gentle and repeated pipetting or with additional collagenase and incubation for $3-5 \mathrm{~min}$ at $37^{\circ} \mathrm{C}$ followed by gentle pipetting. Adult mouse, rat and canine islets as well as human neisidioblastic neonatal islets were isolated according to previously described methods [15-17] and dissociated as described above.

Isolated islet cells were placed in PBS buffer containing $0.2 \%$ (w/v) trypan blue (Gibco, Grand Island, NY, USA) or a combination of AO (Sigma, St. Louis, Mo, USA) and PI (Sigma) in PBS buffer. Stained cells were examined using a $10 \mathrm{X} / 0.4$ NA Wild Fluotar phase contrast lens on an inverted Wild M40 microscope equipped for phase contrast and epi-illumination fluorescent microscopy. An FITC filter set (Ex490: Em510) permitted the simultaneous visualization of green and red fluorescing cells.

Since high concentrations of many dyes are toxic to cells, a serial dilution of $\mathrm{AO}$ and $\mathrm{PI}$ was made over the concentration range of $0.67-12,500 \mu \mathrm{mol} / 1$ and the fluorochromes were tested on freshly isolated rat islet cells to determine the useful concentration range for each fluorochrome. Low concentrations of $\mathrm{AO}(0.67 \mu \mathrm{mol} / 1)$ and PI $(75 \mu \mathrm{mol} / 1)$ were used for the AO/PI assay because they resulted in a bright cellular fluorescence while minimizing extracellular fluorescence.

Once the optimal staining conditions for $\mathrm{AO} / \mathrm{PI}$ were determined, this assay was compared to the trypan blue dye exclusion assay performed under "optimal conditions". Dissociated rat islet cells were stained with $\mathrm{AO} / \mathrm{PI}$ for $60 \mathrm{~min}$ and the percentage of cells which fluoresced green were compared with the percentage of the same population of cells which excluded trypan blue after $5 \mathrm{~min}$.

To determine if the dyes were toxic, dissociated rat islet cells were exposed to either AO/PI or trypan blue for 60 and $5 \mathrm{~min}$, and the mean viabilities were compared. After exposure to the fluorochromes, the cells were placed in the dark at room temperature. Cell counts of trypan blue or AO/PI stained islet cells were made after 5 and $60 \mathrm{~min}$. At least 100 cells were counted per replicate, and a minimum of 3 replicates were counted per experiment to determine the mean percent viable cells.

To determine if the AO/PI assay could be applied to islet cells isolated from other species, dissociated cells from adult mouse, adult dog, and human neonatal islets were observed after staining with $\mathrm{AO} / \mathrm{PI}$ or trypan blue for 5 or $60 \mathrm{~min}$.

To assay the viability of intact islets, individual islets were placed into separate wells of a 96 well microtiter plate, and stained with $\mathrm{AO} / \mathrm{PI}$. Staining time and dye concentration was identical to that described above. Each islet was classified according to its fluorescent colours. The criteria used for islet selection were: type A (>90\% green), type B (40-60\% green), or type C ( $>90 \%$ red). To confirm the interpretation that live islet cells fluoresce green, and dead islet cells fluoresce red, dissociated islet cells were stained for $5 \mathrm{~min}$ with $\mathrm{AO} / \mathrm{PI}$ and photographed with fluorescence microscopy. Next the islets were washed free of $\mathrm{AO} / \mathrm{PI}$, stained for $5 \mathrm{~min}$ with trypan blue, and rephotographed with phase contrast microscopy.

\section{Statistical analysis}

An unpaired Student's t-test was used to test for differences between the means. All experiments on rat cells were repeated three times with three replicates per experiment. To determine if the AO/PI assay was reproducible, the within-assay coefficients of variation $(\mathrm{CV} \%)$ were determined in the 6 separate experiments.
Table 1. Effect of fluorochrome concentrations on rat islet cells

\begin{tabular}{|c|c|c|c|c|}
\hline \multirow{3}{*}{$\begin{array}{l}\text { Concentration } \\
\text { [umol/1] }\end{array}$} & \multicolumn{4}{|l|}{ Fluorescence } \\
\hline & \multicolumn{2}{|l|}{$\overline{\mathrm{AO}^{\mathrm{a}}}$} & \multicolumn{2}{|l|}{$\mathrm{PI}^{\mathrm{b}}$} \\
\hline & Background & Cells & Background & Cells \\
\hline 0.67 & clear & green & clear & no uptake \\
\hline 1.5 & clear & green & clear & no uptake \\
\hline 10 & clear & green & clear & no uptake \\
\hline 20 & clear & red & clear & no uptake \\
\hline 40 & green & red & clear & no uptake \\
\hline 90 & green & red & clear & no uptake \\
\hline 190 & green & red & clear & no uptake \\
\hline 390 & green & red & clear & no uptake \\
\hline 780 & green & red & clear & no uptake \\
\hline 1.560 & green & red & red & red \\
\hline 3.130 & green & red & red & red \\
\hline 6.250 & green & red & red & red \\
\hline 12.500 & green & red & red & red \\
\hline
\end{tabular}

${ }^{a}$ Acridine Orange (AO) enters live cells and fluoresces green at low dye concentrations. At concentrations $\geq 20 \mu \mathrm{mol} / 1$, the intracellular fluorescence undergoes a metachromatic shift from green to red. At $\mathrm{AO}$ concentrations $\geq 40 \mu \mathrm{mol} / 1$, an intense green extracellular background obscured the fluorescent cells. ${ }^{b}$ Propidium Iodide (PI) stains the nuclei of dead and dying cells bright red. At concentrations $\geq 1,560 \mu \mathrm{mol} / 1$, both background and cellular staining was an intense red. At concentrations $\leq 780 \mu \mathrm{mol} / 1$, viable cells excluded dye and the background fluorescence was minimal

\section{Results}

Table 1 shows the effects of varying either acridine orange or propidium iodide concentrations on intracellular and extracellular fluorescence in rat islet cell preparations. When these cells were exposed to $\geq$ $20 \mu \mathrm{mol} / 1 \mathrm{AO}$, an intracellular metachromatic shift from green to red fluorescence was observed. At $\mathrm{AO}$ concentrations $\geq 40 \mu \mathrm{mol} / \mathrm{l}$ islet cells were more difficult to recognise against a bright green background of extracellular fluorescence. At a concentration of $0.67 \mu \mathrm{mol} / 1 \mathrm{AO}$, islet cells fluoresced a bright green colour with very little extracellular fluorescence.

When high concentrations of propidium iodide were used, alone, $(\geq 1560 \mu \mathrm{mol} / \mathrm{l})$ resulted in a bright red extracellular fluorescence (Table 1). At lower dye concentrations extracellular fluorescence was progressively reduced, and fluorescent cells were discernable. At a concentration of $75 \mu \mathrm{mol} / 1$ PI [12], dead and dying islet cells fluoresced a bright red colour with a low extracellular fluorescence.

Table 2 compares AO/PI and trypan blue staining of dissociated rat islet cells. There was no significant difference between $\mathrm{AO} / \mathrm{PI}$ and trypan blue viability estimates at $5 \mathrm{~min}(p>0.05)$. The $\mathrm{AO} / \mathrm{PI}$ assay was not cytotoxic to dissociated rat islet cells, since the 5 and 60 min viability remained constant $(p>0.05)$. The AO/ PI assay was stable with time $(p>0.05)$ while the trypan blue assay was not.

In addition to being an accurate, non-toxic, and stable assay, the AO/PI assay is reproducible. Replicate counts were similar as shown by small interassay 


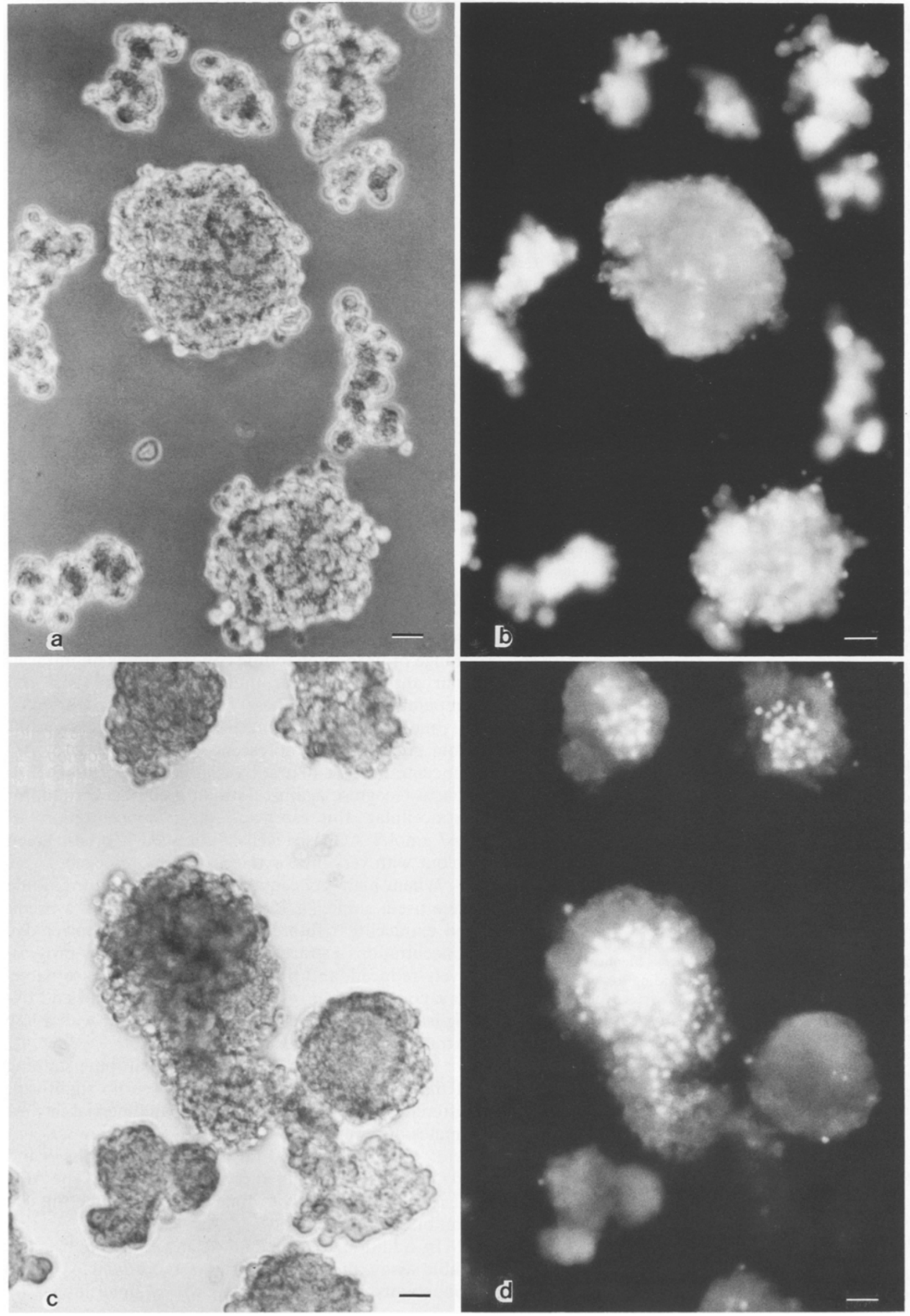


Table 2. Stability of trypan blue and $\mathrm{AO} / \mathrm{Pl}^{\mathrm{a}}$ stained rat islet cells

\begin{tabular}{lcll}
\hline Experiment & $\begin{array}{c}\text { Time } \\
(\mathrm{min})\end{array}$ & Trypan blue & AO/PI \\
\hline 1 & $5^{\mathrm{b}}$ & $80.4 \pm 0.9^{\mathrm{c}}$ & $80.7 \pm 2.3^{\mathrm{c}}$ \\
& $60^{\mathrm{d}}$ & $70.4 \pm 2.8$ & $79.7 \pm 0.7$ \\
2 & 5 & $55.1 \pm 1.3$ & $61.4 \pm 4.3$ \\
& 60 & $29.6 \pm 2.5$ & $66.5 \pm 4.1$ \\
3 & 5 & $85.7 \pm 0.2$ & $82.0 \pm 2.4$ \\
& 60 & $56.4 \pm 1.7$ & $82.0 \pm 2.8$ \\
\hline
\end{tabular}

${ }^{a}$ Acridine orange $(0.67 \mu \mathrm{mol} / \mathrm{l})$ and propidium iodide $(75 \mu \mathrm{mol} / 1)$ in PBS buffer. ${ }^{b}$ After $5 \mathrm{~min}$ of exposure there was no significant difference between the number of cells which excluded trypan blue or fluoresced green after exposure to $\mathrm{AO} / \mathrm{PI}$. ${ }^{\circ}$ The mean percent of cells $\pm \mathrm{SE}$ with an intact plasma membrane after staining. ${ }^{\mathrm{d}}$ There was no change in the number of cells which fluoresced green after 5 or 60 min exposure to $\mathrm{AO} / \mathrm{PI}(p>0.05)$. The number of positively stained cells increased between 5 and $60 \mathrm{~min}$ of exposure to trypan blue $(p<0.05)$

Table 3. Viability of rat, mouse, dog and human islet cells stained with trypan blue or $\mathrm{AO} / \mathrm{PI}^{\mathrm{a}}$

\begin{tabular}{lcll}
\hline Species & $\begin{array}{c}\text { Time } \\
(\mathrm{min})\end{array}$ & Trypan blue & AO/PI \\
\hline Rat & $5^{\mathrm{b}}$ & $85.7 \pm 0.2^{\mathrm{c}}$ & $82.0 \pm 2.4^{\mathrm{c}}$ \\
& $60^{\mathrm{d}}$ & $56.4 \pm 1.7$ & $82.0 \pm 2.8$ \\
Mouse & 5 & $86.5 \pm 2.7$ & $82.8 \pm 3.8$ \\
& 60 & $58.9 \pm 8.4$ & $84.2 \pm 3.3$ \\
Dog & 5 & $60.3 \pm 6.3$ & $76.5 \pm 6.5$ \\
& 60 & $39.3 \pm 6.1$ & $67.7 \pm 5.7$ \\
Human & 5 & $87.0 \pm 1.4$ & $85.5 \pm 1.9$ \\
& 60 & $65.5 \pm 3.9$ & $84.4 \pm 0.8$ \\
\hline
\end{tabular}

a Acridine orange $(0.67 \mu \mathrm{mol} / \mathrm{l})$ and propidium iodide $(75 \mu \mathrm{mol} / \mathrm{l})$ in PBS buffer. ${ }^{b}$ Regardless of species, there was no significant difference between the number of cells which stained blue after exposure to trypan blue for $5 \mathrm{~min}$ and the number of cells which fluoresced green after exposure to $\mathrm{AO} / \mathrm{PI}$ for 5 or $60 \mathrm{~min}(p>0.05)$. ${ }^{\mathrm{c}}$ The mean percent of cells $\pm \mathrm{SE}$ with an intact plasma membrane after staining (3 replicate samples). ${ }^{d}$ A significant increase occurred in the number of cells which stained blue after exposure to trypan blue for $5 \mathrm{~min}$ and $60 \mathrm{~min}(p<0.05)$

coefficients of variations (CV\%) for 6 separate experiments $(5.3 \%, 3.2 \%, 2.6 \%, 2.9 \%, 6.2 \%, 4.3 \%)$.

When the assay was tested on three other species human, canine, murine - the results with $\mathrm{AO} / \mathrm{PI}$ and trypan blue were similar. The number of green fluorescing cells after 5 or $60 \mathrm{~min}$ exposure to $\mathrm{AO} / \mathrm{PI}$ were similar to the number of cells excluding trypan blue after $5 \mathrm{~min}$ exposure to the dye $(p>0.05)$. However the number of trypan blue stained cells increased over the same time interval regardless of species tested $(p<$ 0.05 , Table 3).

The fluorescent images of intact islets result from the fluorescence of its component cells. The islets can be classified into three basic groups; type $A$ islets have a relatively uniform green fluorescence. In freshly isolated islets, a few peripheral yellow or red pancreatic acinar cells are often seen. Type B islets have many distinct yellow-coloured cells while type $\mathrm{C}$ islets fluoresce uniformly red (Fig.1).

\section{Discussion}

Chromogenic inclusion dyes such as neutral red and exclusion dyes such as trypan blue are commonly used to assay the membrane integrity of numerous cell types [18-20]. However, these dyes have a limited usefulness for evaluating islet cells [12]. Our results agree with previous reports that the percentage of cells stained with trypan blue increases with time [22-25]. The constraints of a 5-10 min window of stability for trypan blue limits the number of samples that can be stained at a single time. The combination of $\mathrm{AO} / \mathrm{PI}$ permits the observation of intact and damaged cells simultaneously. The similarity of the results of the AO/PI assay and the trypan blue assay indicates that the $\mathrm{AO} / \mathrm{PI}$ assay is at least as sensitive as the classic dye exclusion test for cell viability.

Cells with intact vs compromised plasma membranes are easily discriminated using the $\mathrm{AO} / \mathrm{PI}$ assay (green vs red). The AO/PI assay [5] gives similar results to the trypan blue assay (using 5 min staining time) [6]; produces quantitatively reliable results [8]; the proportion of AO stained cells remains constant after exposure to the dye for at least $60 \mathrm{~min}$ [9]; the dyes are not cytotoxic to islet cells for at least $1 \mathrm{~h}$ [10]; the assay is precise (low within-assay coefficient of variation) [11].

The AO/PI assay is capable of simultaneously visualizing live and dead cells in intact islets. Since live cells fluoresce a bright green and dead cells fluoresce a bright red the assay is sensitive enough to detect individual dead cells within an islet composed of thousands of living cells. In our laboratory, the primary use of the assay is to rapidly sample the viability of a population of islets prior to the onset of a time-consuming experiment. This screening assay allows a judgment to be made on the condition of a population of islets prior to experiments.

Fig. 1a d. Four low power light micrographs showing the appearance of freshly isolated islets viewed by phase contrast (a, c) and the same field of islets viewed by fluorescent microscopy $(b, c)$. The small bright spots in the fluorescent micrographs correspond to the intense red staining of the propidium iodide positive (dead) cells. The diffusely stained regions correspond to the AO stained (live) cells. Despite the similar appearance of $\mathbf{a}$ and $\mathbf{c}$ in bright field or phase contrast, the damaged islets are readily distinguished after AO/PI staining (b vs d). All photographs were taken with a $10 \mathrm{X}$ objective and photographically enlarged to 600 diameters $(\mathrm{bar}=10 \mu \mathrm{mol} / \mathrm{l})$ 
The conformation that the fluorescent colours are related to the physiological condition of intact islets will be reported separately [21]. Briefly, the insulin content of green type A islets are identical to untreated islets and these islets have normal ultrastructural morphology. Red type $C$ islets had little or no insulin and showed disrupted cell membranes and no cytoplasmic granules when viewed by electron microscopy. Yellow type $\mathrm{C}$ islets had an intermediate insulin content and heterogenous ultrastructural appearance.

The appearance of cells stained with $\mathrm{AO} / \mathrm{PI}$ is comparable to cells stained with fluorescein diacetate and ethidium bromide (the FDA/EB assay), but AO has the advantage that the pattern of fluorescence reveals nuclear morphology. This allows identification and exclusion of contaminating leukocytes, such as eosinophils and polymorphonuclear neutrophils, from the count of viable islet cells. An additional application of the $\mathrm{AO} / \mathrm{PI}$ assay is testing the viability of mononuclear cells. For example, this laboratory recently reported excellent agreement between the $\mathrm{AO} / \mathrm{PI}$ assay results and the blastogenic potential of lymphocytes as well as the ability of macrophages to secrete lysozyme [22].

This AO/PI assay is not designed as a quantitative replacement for more traditional assays such as glucose sensitive insulin release. Rather, this assay enables the investigator to estimate the viability of a preparation of islet cells prior to time-consuming experiments rather than retrospectively.

In conclusion, the $\mathrm{AO} / \mathrm{PI}$ assay was used to visualize live and dead islet cells simultaneously. AO stains the live cells green while PI stains dead cells red. A major advantage of the $\mathrm{AO} / \mathrm{PI}$ assay is that viability can be assessed even $60 \mathrm{~min}$ after staining and yield reproducible results. The $\mathrm{AO} / \mathrm{PI}$ assay can be used to determine the viability of isolated rat islet cells, and preliminary studies show that similar results with islet cells isolated from adult rat, murine, canine, and neonatal neisidoblastic human islets.

Acknowledgements. I wish to acknowledge the technical assistance of Dr. P.Moore and Ms R. Didiyk, Drs. G. Bright and A.J. Garvin for providing the human neonatal pancreatic tissue, Dr. B. Loadholt for his comments and assistance in the statistical analyses of the data and Ms M.Jackson-Gegan for her editorial comments. Research supported in part by NIH grant OK 18115

\section{References}

1. Edidin M (1970) A rapid, quantitative fluorescence assay for cell damage by cytotoxic antibodies. J Immunol 104: 1303-1306

2. Mohr LR, Trounson AO (1980) The use of fluorescein diacetate to assess embryo viability in the mouse. J Reprod Fertil 58: 189-196

3. Rotman B, Papermaster BW (1966) Membrane properties of living mammalian cells as studied by enzymatic hydrolysis of fluorogenic esters. Proc Natl Acad Sci USA 55: 134-141

4. Bank HL (1980) Viability of frozen rat granulocytes and granulocyte precursors. Cryobiology 17: 262-272

5. Pantazis CG, Kniker WT (1979) Assessment of blood leukocyte microbial killing by using a new fluorochrome microassay. J Reticuloendothel Soc 26: 155-170

6. West SS (1969) Fluorescence microspectrophotometry of supravitally stained cells. In: Pollister AW (ed) Physical techniques in biological research, 2nd ed, Vol $3 \mathrm{c}$. Academic Press, New York, pp 253-321

7. Kapuscinski J, Darzynkiewicz Z, Melamed MR (1983) Interactions of acridine orange with nucleic acids. Properties of complexes of acridine orange with single stranded ribonucleic acid. Biochem Pharmacol 32: 3679-3694

8. Waring M (1975) Ethidium and propidium. In: Corcoran JW, Hahn FE (eds) Antibiotics III. Mechanism of action of antimicrobial and antitumor agents. Springer, New York, pp 141-165

9. Yeh C-JG, Hsi B-L, Faulk WP (1981) Propidium iodide as a nuclear marker in immunofluorescence. II. Use with cellular identification and viability studies. J Immunol Methods 43: 269-275

10. Tanke HJ, Van der Linden PWG, Langerak J (1982) Alternative fluorochromes to ethidium bromide for automated read out of cytotoxicity tests. J Immunol Methods 52: 91-96

11. Jacobs DB, Pipho C (1983) Use of propidium iodide staining and flow cytometry to measure antibody-mediated cytotoxicity: resolution of complement-sensitive and resistant target cells. J Immunol Methods 62: 101-108

12. Moore PL, Didyk R, Bank HL (1985) The rapid assessment of viability of isolated islets of Langerhans with fluorescent dyes: relationship between fluorescent images and insulin content. J Cell Biol 101: 247a

13. Lacy PE, Walker MM, Fink CJ (1972) Perifusion of isolated rat islets in vitro: participation of the microtubular system in the biphasic release of insulin. Diabetes 21: 987-998

14. Bank HL, Davis RF, Emerson D (1979) Cryogenic preservation of isolated rat islets of Langerhans: effect of cooling and warming rates. Diabetologia 16: 195-199

15. Gray DW, McShane P, Grant A, Morris PJ (1984) A method for isolation of islets of Langerhans from the human pancreas. Diabetes 33: 1055-1061

16. Gotoh M, Maki T, Kiyoizumi T, Satomi T, Monaco AP (1985) An improved method for isolation of mouse pancreatic islets. Transplantation 40: 437-438

17. Horaguchi A, Merrell RC (1981) Preparation of viable islet cells from dogs by a new method. Diabetes 30: 455-458

18. Hutz RJ, DeMayo FJ, Dukelow WR (1985) The use of vital dyes to assess embryonic viability in the hamster, Mesocricetus Auratu. Stain Technol 60: 163-167

19. Dolan MF (1965) Viability assays - a critique. Fed Proc 24 [Suppl]: S275-279

20. Klebe RJ (1984) Rapid cloning of mammalian cells with honeycomb cloning plates and nonlethal vital stains. In Vitro 20: $127-132$

21. Bank HL (1988) The rapid assessment of islet viability with Acridine orange and propidium iodide. In Vitro 24 (in press)

22. Taylor MJ, Bank HL, Benton MJ (1987) Selective destruction of leukocytes by freezing as a potential means of modifying tissue immunogenicity: membrane integrity of Lymphocytes and Macrophages. Cryobiology 24: 91-102

23. Albright BL, Selinger DS, Reed WP (1979) Use of vital stains to study bacterial adherence to epithelial cells. Stain Technol 54: 347-349

24. Black L, Berenbaum MC (1964) Factors affecting the dye exclusion test for cell viability. Exp Cell Res 35: 9-13

25. Tennant JR (1964) Evaluation of the trypan blue technique for determination of cell viability. Transplantation 2: 685-694

Received: 4 May 1987

and in revised form: 11 August 1987

Dr. Harvey Bank

Department of Pathology

Medical University of South Carolina

Charleston, SC 29425

USA 